\title{
Primary Aorto-Duodenal Fistula with Enterococcus Foecalis Infection: A Rare But Life Threatening Etiology of Gastro-Intestinal Bleed
}

\author{
Antoine Abou Rached ${ }^{1 *}$, Joyce Sanyour ${ }^{1}$, Leila Al Masri ${ }^{1}$, Mary Nakhoul ${ }^{1}$ and Naji Ayle ${ }^{2}$ \\ ${ }^{1}$ Department of gastroenterology, Faculty of Medical Sciences, Lebanese University, Hadath, Lebanon \\ ${ }^{2}$ Cardio-vascular surgery Department, Saint Charles Hospital, Fayadieh, Lebanon
}

\begin{abstract}
Received: December 12, 2017; Accepted: January 17, 2018; Published: January 22, 2018
*Corresponding author: Antoine Abou Rached, Gastroenterologist, Faculty of Medical Sciences, Lebanese University, Hadath, Lebanon, Tel: +9613746317; E-mail: abourachedantoine@gmail.com
\end{abstract}

\begin{abstract}
Aortoduodenal fistula is a rare and serious condition. It can be primary and secondary. Clinical presentation is characterized by the classic triad of GI bleed, abdominal pain and palpable abdominal mass that occur in only $11 \%$ of cases. Accurate and rapid diagnosis should be considered since any delay has a deleterious effect on patient's life. We are reporting a case of primary aortoduodenal fistula presenting initially with acute and massive GI bleed.
\end{abstract}

\section{Introduction}

Aorto Duodenal Fistula (ADF) is a rare entity but lifethreatening condition; it is classified either as primary aortoduodenal fistula (PADF) that develops between the aorta and the third or fourth portion of the duodenum without prior reconstructive procedures on the abdominal aorta and can be the cause of massive gastrointestinal (GI) bleeding, and secondary ADF produced by erosion of an aortic prosthesis into the digestive tract [1]. PADF It is first described by Cooper in 1822 [2].The first case report was described by Salmon in 1843 [3].

\section{Case report}

A 71 years old male patient previously healthy, smoker, nonalcohol consumer presented initially for 1 day history of painless bright red blood per rectum. Patient denied gastro-intestinal, respiratory or urinary symptoms. To note that 2 months prior to this presentation he reports having left lower quadrant pain radiating to the back treated occasionally with non-steroidal antiinflammatory (NSAIDS) and antalgic medications.

Upon presentation his physical examination revealed a temperature of 36.9 degrees, Blood Pressure of110/70 mmHg with tachycardia of $107 \mathrm{bpm}$ and saturation of $97 \%$. The pertinent findings on his physical exam were a pulsatile abdominal mass without tenderness or guarding.

Laboratory investigation was significant for anemia with hemoglobin of $6.8 \mathrm{~g} / \mathrm{dl}$ and increase in white blood cell with 21 770 and C-reactive protein of $28.6 \mathrm{mg} / \mathrm{l}$ (normal $<5 \mathrm{mg} / \mathrm{l}$ ), also we found coagulation defect with an INR of 1.34, hypoalbuminemia of $2.9 \mathrm{~g} / \mathrm{dl}$ and creatinine $1.87 \mathrm{mg} / \mathrm{dl}$

The Esophagogastroduodenoscopy till the second duodenum was normal. The ultrasound showed an abdominal aortic aneurysm of $7.2 \mathrm{~cm}$ with a thrombus found in the right anterolateral lumen of the aneurysm, bilateral common iliac arteries aneurysm of $4.7 \mathrm{~cm}$ on the right and $3.7 \mathrm{~cm}$ on the left side and right hypogastric artery aneurysm of 6 ? $\mathrm{cms}$.

An abdomino-pelvic Computed Tomography scan without intravenous injection (creatinine $=1,87 \mathrm{mg} / \mathrm{dl}$ ) was done and showed the same result of the ultrasound with a close contact of the aneurysm with the fourth portion of the duodenum (Figure 1,2 and 3 )

Arteriography was deferred since the patient had kidney injury with a creatinine level of $1.87 \mathrm{mg} / \mathrm{dl}$. In view of these findings, an aorto-duodenal fistula was suspected and vascular surgery team was consulted and urgent laparotomy was scheduled. Intraoperatively, an infrarenal abdominal aortic aneurysm was seen, extending to the iliac arteries bilaterally associated with an aortoduodenal fistula between the aneurysm and the 4th of duodenal segment; The Duodenum was closed adequately by sutures followed by placement of a Dacron graft between the aorta and external iliac arteries with exclusion of the aorta, both common iliac arteries and the right hypogastric artery aneurysms; the left hypogastric artery is retrogradely vascularized by the left external iliac artery. Culture of the fistula was positive for Enterococcus Foecalis treated with IV antibiotics for 2 weeks than switched to PO treatment. The First follow-up at the outpatient clinic, fifteen days after discharge, shows normal vital signs and physical examination.

\section{Discussion}

We report a case of primary aorto duodenal fistula presenting with lower GI bleed, secondary to infected aneurysm with Enterococcus foecalis treated surgically and medically with good final outcome. 

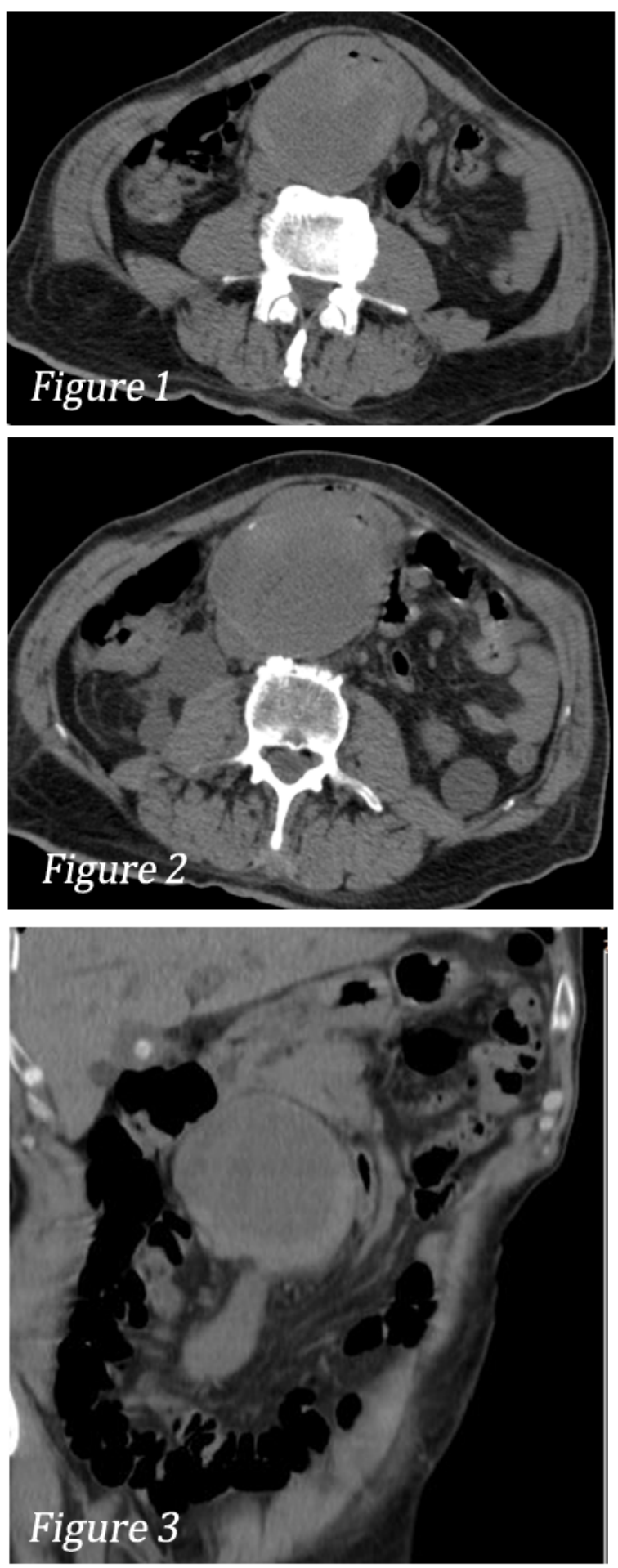

Figure 1, 2, and 3: CT scan abdomen without IV contrast showed heterogeneous abdominal aortic aneurysm of $7 \mathrm{~cm}$ and its direct contact with 4th duodenal segment suspecting the presence of fistula
Till date less than 300 cases of PADF have been reported in the literature [4]. The incidence of PADF is 0.04-0.07\% [5]. Aneurysm constitutes $70 \%$ of cases, but aortitis (infectious or inflammatory) can be a cause $[6,7]$. Other possible factors are tumors, foreign body, radiotherapy, diverticulitis, appendicitis, gallstones, ulcers and infection mainly salmonella and klebsiella but sometimes tuberculosis, syphilis, mycosis, streptococcus and staphylococcus $[2,4,6,7]$. In addition, case reported by Dilek et al showed PADF in patient with rheumatoid arthritis on steroid therapy which can be the risk factor of connective tissue fragility and fistula formation [4].

The fistula may occur in other region of the GI tract such as esophagus, jejunum, ileum and colon $[2,8]$. The GI bleed is the most common and serious clinical presentation (64\%) and maybe associated with abdominal pain $(32 \%)$ or palpable mass $(25 \%)$ $[2,9]$. This classic triad is only found in $11 \%$ of patients [6]. The severe GI bleeding and hemorrhagic shock can be preceded hours to weeks by "herald bleeds" that are mild and self-limited $[3,10]$.

The diagnosis is difficult due to nonspecific clinical presentation. CT scan, endoscopy and angiography can be used $[3,11]$. Ct scan, the most suitable diagnostic test when PADF is suspected, can show air in the retro peritoneum with loss of aneurysmal wall and disappearance of the fat between the aneurysm and the duodenum and sometimes contrast leakage into the GI tract which is pathognomonic finding [2, 12]. Endoscopy can only be performed if hemodynamically stable patient and negative result does not rule out PADF because it does not allow visualization of the distal duodenum $[2,13]$. It is mainly used to rule out other causes of upper GI bleed [2]. Angiography is not reliable in diagnosis PDAF. Magnetic resonance imaging, ultrasound, colonoscopy and tagged white blood cell scans are of limited value [14].

Even with surgical treatment, the mortality is 18 to $93 \%$ [4]. PADF associated with infected aneurysm has a worse prognosis than ADF associated with aneurysm alone with postoperative mortality more than $50 \%$ [2].

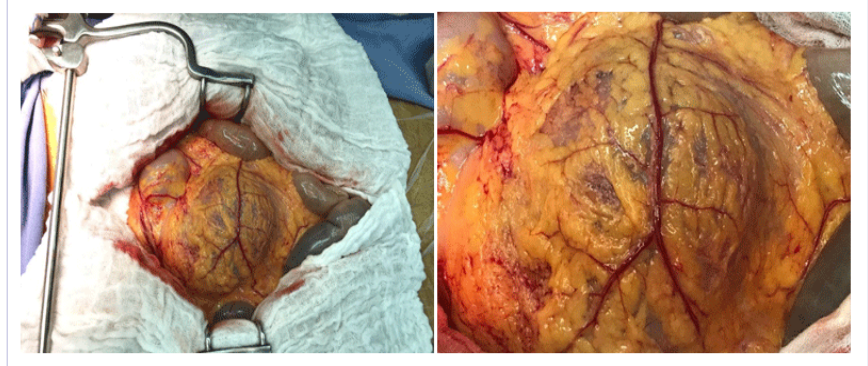

Figure 4: Intraoperative aorto abdominal aneurysm

\section{Conclusion}

In summary, the presentation of primary aorto duodenal fistula could be very challenging without previous history of selflimited bleed or the classical triad of GI bleed, pain and abdominal palpable mass, making a delayed and difficult diagnosis. Although the most used diagnostic tools are CT scan of the abdomen 
and pelvis, EGD and arteriography, the etiology of bleed could be missed and the last resort would be urgent exploratory laparotomy.

\section{References}

1. Mircea Beuran, Ionut Negoi, Ruxandra Irina Negoi, Sorin Hostiuc, Sorin Hostiuc. Primary Aortoduodenal Fistula: First you Should Suspect it. Braz J Cardiovasc Surg. 2016;31(3):261-263. Doi: 10.5935/16789741.20160049

2. Lemos DW, Raffetto JD, Moore TC, Menzoian JO. Primary aortoduodenal fistula: A case report and review of the literature. J Vasc Surg. 2003;37(3):686-689.

3. Šumskienė J, Šveikauskaitė E, Kondrackienė J, Limas Kupčinskas. Aortoduodenal fistula: a rare but serious complication of gastrointestinal hemorrhage. A case report. Acta Medica Litu. 2016;23(3):165-168 doi: 10.6001/actamedica.v23i3.3380

4. Dilek Kuzukıran, İsmail Sert, Emre Turgut, Yahya Capkis, Fuat İpekci. Primary Aortoduodenal Fistula in Patients with Rheumatoid Arthritis. 2017. DOI: $10.5152 /$ clinexphealthsci.2017.261

5. Shulik O, Marling K, Butler J. Primary aorto-enteric fistula - a unique complication of poorly differentiated large B-cell lymphoma. Am J Case Rep. 2013;14:194-197. doi: 10.12659/AJCR.889277

6. Fredy Nehme, Kyle Rowe, Cyrus Munguti, and Imad Nassif. A Rare Cause of Primary Aortoenteric Fistula: Streptococcus parasanguinis Aortitis. Case Reports in Gastrointestinal Medicine. 2017;(2017):3.
7. Morrow C, Safi H, Beall AC. Primary aortoduodenal fistula caused by Salmonella aortitis. J Vasc Surg. 1987;6(4):415-418.

8. Gordon AC, Agarwal M. Primary aorto-enteric fistula. Int J Surg Case Rep. 2016;19:60-62. doi: 10.1016/j.ijscr.2015.12.009

9. Sweeney MS, Gadacz TR. Primary aortoduodenal fistula: manifestation, diagnosis, and treatment. Surgery. 1984;96(3):492-497.

10.van Olffen TBM, Knippenberg LHA, van der Vliet JA, Lastdrager WB. Primary Aortoenteric Fistula: Report of Six New Cases. Cardiovasc Surg. 2002;10(6):551-554.

11.Connolly JE, Kwaan JH, McCart PM, DA Brownell, and EF Levine. Aortoenteric fistula. Ann Surg. 1981;194(4):402-412.

12.Alzobydi AH, Guraya SS. Primary aortoduodenal fistula: A case report. World J Gastroenterol. 2013;19(3):415-417. doi: 10.3748/wjg.v19. i3.415

13.Wijeyaratne SM, Ubayasiri R, Weerasinghe C. Haematemesis due to primary aortic aneurysm-duodenal fistula - clinical suspicion is the cornerstone of diagnosis: a case report. Cases J. 2009;2:7803. doi: 10.4076/1757-1626-2-7803

14.Alzobydi AH, Guraya SS. Primary aortoduodenal fistula: A case report. World J Gastroenterol. 2013;19(3):415-417. doi: 10.3748/wjg.v19. i3.415 